\title{
The Status Quo and Analysis of Residents' Financial Management — Taking Guangdong as an Example
}

\author{
Yu Zeng ${ }^{1, *}$ \\ ${ }^{1}$ Guangdong Nanhua Vocational College of Industry and Commerce, Guangzhou, Guangdong, China \\ *Corresponding author. Email: 695722459@qq.com
}

\begin{abstract}
With the development of China's economy and the increase of residents' disposable income, investment and financial management have increasingly entered the lives of residents. However, China's financial market is still undergoing transformation and there are many weak links. At the same time, there are many misunderstandings and problems in residents' investment and financial management, which restricts the effective income of residents' investment and financial management and the sustainable development of economy. Taking Guangdong Province as an example, starting from the current situation of residents' financial management in Guangdong, this paper explores the problems of residents' financial management with the use of empirical analysis method, and puts forward relevant suggestions.
\end{abstract}

Keywords: Residents in Guangdong Province, Investment and financial management, Financial management attitude, Status quo of financial management, Difficulties in financial management.

\section{INTRODUCTION}

The national 14th five-year plan clearly puts forward that it is necessary to form a strong domestic consumer market to promote consumption, the core of improving residents' consumption is to improve residents' income, and further strengthening the investment function of capital market is of great significance to improve residents' financial investment income. In recent years, with the continuous, stable, high-speed and high-quality development of the overall economy in Guangdong Province, the per capita disposable income of Guangdong residents shows a sustained growth, and the people's financial demand has also increased. However, there have been a series of investment cases such as illegal fund-raising, reflecting the common problems such as people's weak understanding of financial knowledge and lack of awareness of investment risk[1]. At present, the weak education of national investment, financial management and the institutional investors is the main reason for the current investors' lack of investment and financial management knowledge (Comprehensive Development Institute, 2021).
Residents' investment and financial management can not only fully stimulate the domestic demand of financial investment and promote the sustainable development of the financial market, but also play an important role in the economic development and transformation of China's financial enterprises. Therefore, it is of great practical significance and practical value to explore the related problems of residents' investment and financial management.[7]

Through a questionnaire survey of residents in Guangdong Province, this paper explores their cognition, attitude, view and current situation of financial management, studies the problems encountered in the process of residents' financial management, puts forward relevant suggestions, and also supplements the deficiencies of empirical research related to the development of Guangdong financial market.[2]

\section{SURVEY SCHEME DESIGN}

\subsection{Investigation Methods}

This paper adopts the combination of field survey and online questionnaire survey. 2200 questionnaires are sent out, 2200 questionnaires are 
finally recovered, and 2108 valid questionnaires are available.

\subsection{Respondents}

The survey covers residents in Guangdong Province. The survey areas are divided into Guangzhou, Shenzhen, the Pearl River Delta and other areas according to the research needs.

\subsection{Investigation Contents}

The survey contents mainly include: the cognition, attitude and view of Guangdong residents on "financial management", the current situation and difficulties of financial management.

\subsection{Basic Information of Samples}

The basic information of the sample includes gender, age, education level, industry, annual income and residence.

Among the samples, women accounted for $58.5 \%$ and men accounted for $41.5 \%$. The data analysis showed that only one research variable was related to gender, so the gender data were not screened, and the samples were representative.

The ages of the samples are divided into several levels: under 18 years old, 18-35 years old, 35-60 years old and over 60 years old. The proportion of residents aged 18-35 is the highest, followed by residents aged 35-60, which is a partial normal distribution. The age of 18-35 years old is the focus of this study.

The education levels are divided into five levels and are normally distributed, of which the junior college accounts for the largest proportion.
The residents' industries are divided into 13 industries, including manufacturing, education, accommodation and catering, wholesale and retail, sports and entertainment, accounting for $50 \%$, which is consistent with the current industry distribution. Other industries are also involved, and the samples are representative.

The annual income of residents can be divided into four segments: less than 120000 yuan, 120000300000 yuan, 300000-500000 yuan and more than 500000 yuan. The most residents' annual income is below 120000 yuan, accounting for $52.8 \%$, and most residents have low and middle income.

The number of residents in the Pearl River Delta is the largest $(46.2 \%)$, followed by Guangzhou (24.3\%) and other regions (19.7\%), including Eastern, Western and northern Guangdong. According to the previous study, it is found that there is no significant gap in all aspects in these regions, which are summarized as other regions.[3][4]

\section{ANALYSIS ON RESIDENTS' COGNITION OF "FINANCIAL MANAGEMENT"}

\subsection{Residents' Understanding of "Financial Management"}

Among Guangdong residents' understanding of financial management, the option "general understanding" accounts for the largest proportion, followed by the option "don't know much". And the overall understanding is not high. (as can be seen in "Figure 1")

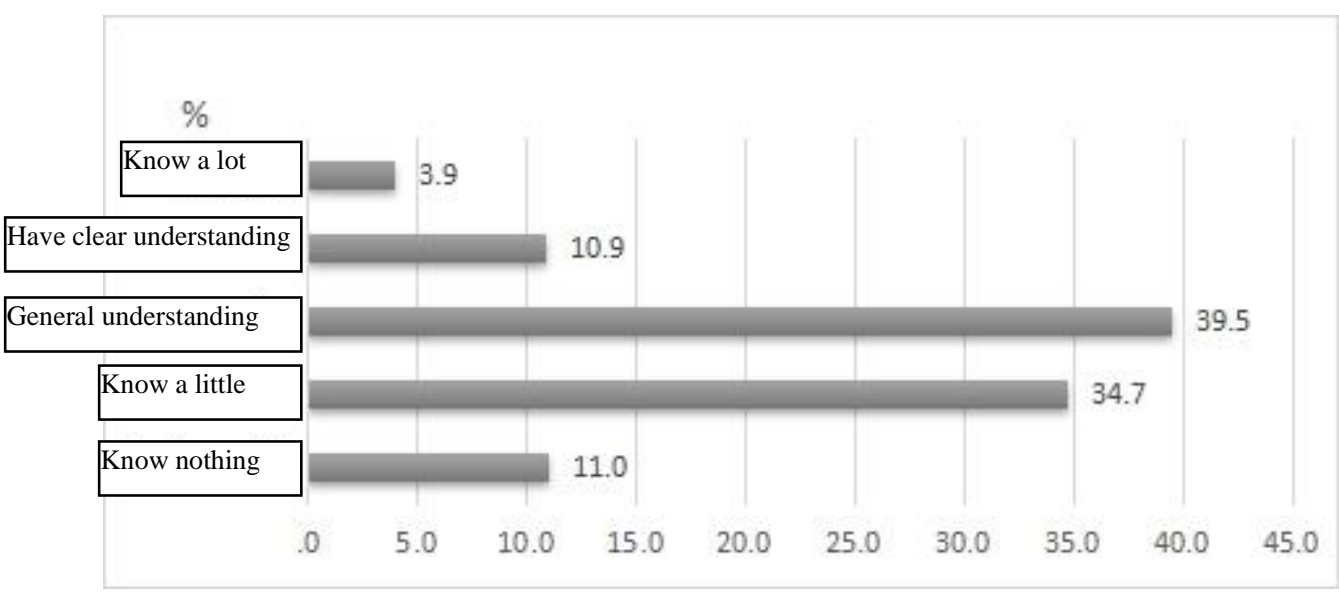

Figure 1 Residents' understanding of financial management in Guangdong Province. 
According to further cross-over analysis, it is found that there are significant differences in the understanding of residents of different income, regions, industries and ages on financial management. The understanding of financial management is positively correlated with income and age; The cumulative sum of the option "have clear understanding" and the option "know a lot" of residents in the Pearl River Delta and Shenzhen $(12.5 \%+5 \%$ and $13.6 \%+3.4 \%$ respectively) is significantly higher than that in Guangzhou (9.4\%) and other regions $(13.3 \%)$; The residents working in manufacturing "know nothing" about the financial management, which accounts for the largest proportion $(22.1 \%)$ among all industries, and the residents of information transmission software and information technology service industries know a lot about the financial management, accounting for $11.5 \%$.

With the popularity of the Internet and the rapid development of Internet finance, Guangdong residents mainly understand financial products through Internet channels, accounting for $61.3 \%$. According to further analysis of the main channels for residents in various regions to understand financial products, there are significant differences in understanding financial products through Internet, school education and other channels in different regions. Among them, Guangzhou residents realize the financial management through school education (23.6\%, the largest proportion), which is mainly affected by many colleges and universities in Guangzhou.

According to further cross-over analysis, it is found that residents with an annual income of less than 120000 yuan know about financial products through the Internet (65.4\%) significantly higher than other residents, while residents with an annual income of 300000-500000 yuan chose publicity channels $(40 \%)$ of financial enterprise to know about financial products significantly higher than other residents. Most of the residents with income below 120000 yuan are young people and rely more on convenient and fast network channels. The residents with an annual income of 300000-500000 yuan are high net worth customers that financial enterprises strive for, and are easier to get the active publicity services of financial enterprises.

\subsection{Residents' Attitudes and Views on Financial Management}

\subsubsection{Residents' Attitude Towards Investment and Financial Management}

As can be seen from "Figure 2", nearly $60 \%$ of the residents in Guangdong Province have a positive attitude towards investment and financial management, and are willing to carry out investment and financial management even if there are risks, which reflect the strong financial management awareness and challenging spirit of Guangdong residents.

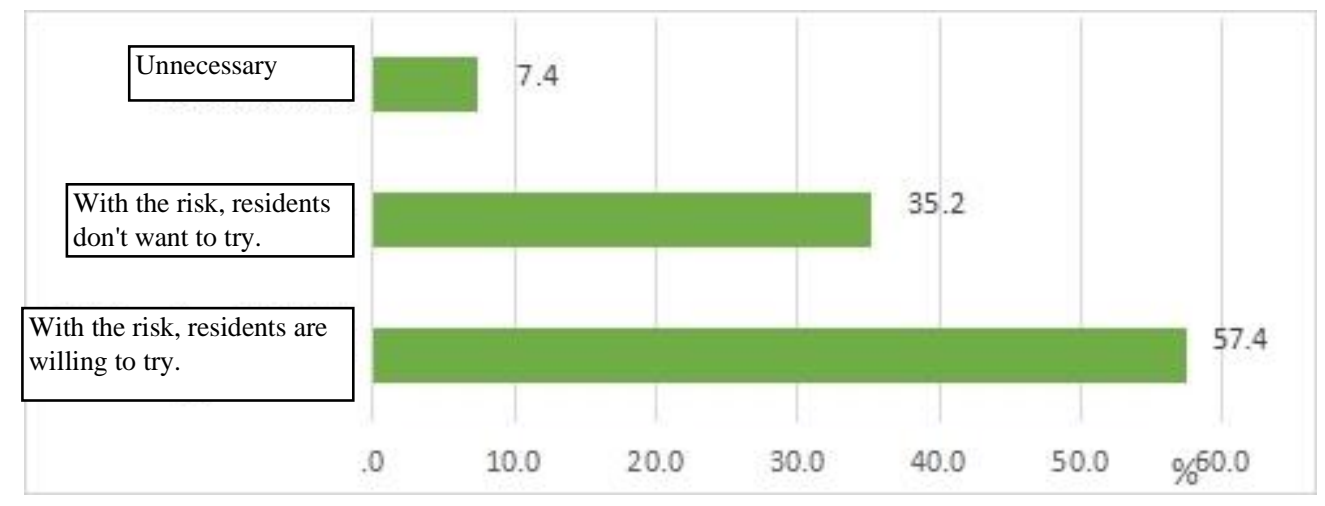

Figure 2 Attitudes of residents in Guangdong Province towards investment and financial management.

According to further cross-over analysis, it is found that the proportion of residents in senior high school, higher vocational school or technical secondary school, junior middle school or below choosing the option "being willing to invest even if there are risks" (66.1\% and $64.6 \%$ respectively) is significantly higher than that of residents with other degrees of educational background. Generally speaking, there is a positive correlation between income level and educational background. Therefore, residents with junior college or below are more eager to increase income and wealth through investment and financial management. From the perspective of industry analysis, the 
proportion of residents working in sports and entertainment industry being willing to invest $(87.2 \%)$ and the proportion of residents engaged in manufacturing industry being afraid to try $(89.7 \%)$ are significantly higher than those in other industries $\quad(p=0.000<0.05, \quad$ Lambda $=0.173)$. Residents in sports and entertainment industry obviously have more advantages in information acquisition, and they have higher investment willingness. It can be seen that residents in different industries hold different attitudes towards risks, which would affect their investment and financial behavior.

\subsubsection{Attitude Towards Investment and Financial Management Under External Influence}

In addition to their own willingness to invest, about $88 \%$ of Guangdong residents' financial behaviors are also affected by the people around them. From the overall results of data analysis, the impact of people around on residents is positive. From further cross-over analysis, it is found that the proportion of residents under the age of 18 years old and 18-35 years old who "dare not invest" (both at $10 \%$ ) is significantly lower than that of residents of other ages $(\mathrm{P}=0.000<0.05)$. It can be seen that even affected by the people around, young people are still very willing to invest and have adventurous spirit. Residents in different industries are significantly affected by the investment and financial behavior of people around $(p=0.000$, Lambda=0.083), and there are significant differences. The proportion of residents engaged in wholesale and retail industry who "dare not invest" is as high as $46.2 \%$. The proportion of residents with an annual income of less than 120000 yuan "participating in investment more carefully under the influence of people around is $41.9 \%$, and the proportion of residents with an annual income of more than 500000 yuan "being willing to invest and manage money under the influence of people around" is as high as $52.6 \%$. It can be seen that affected by people around, the annual income level directly affects their investment behavior and attitude.

\section{CURRENT SITUATION OF RESIDENTS' FINANCIAL MANAGEMENT}

\subsection{Current Situation of Residents' Financial Behavior}

From the statistical results, $64.1 \%$ of residents have no other financial investment behavior except bank savings, which reflects the single and traditional financial means of Guangdong residents, and also means that the financial market potential of Guangdong residents is huge.

According to the survey, it is found that there are significant differences in the current situation of residents participating in investment and financial activities in different residences $(\mathrm{p}=0.000<0.05$, Lambda=0.23). The number of residents living in other areas of Guangdong who are engaged in investment and financial activities accounts for the highest proportion $(87.1 \%)$. The proportion of men $(41.0 \%)$ who are engaged in investment and financial management is significantly higher $(p=0.033<0.05) \quad$ than women $(32.5 \%)$, the proportion of residents working in education $(68.7 \%)$ and finance $(60 \%)$ participating in investment and financial management is significantly higher $(p=0.000<0.05)$ than that of other industries, and the proportion of residents with bachelor degree $(51.7 \%)$ who are engaged in investment and financial management is significantly higher $(\mathrm{p}=0.001<0.05)$ than residents with other education degrees.

\subsection{Current Situation of Residents' Investment and Financial Management Amount}

$88.8 \%$ of the residents in Guangdong Province now invest less than $50 \%$ of their annual household income. There is a positive correlation between age and residents' income available for financial investment $(\mathrm{p}=0.005<0.05$, Gamma=0.475). Further analysis shows that the proportion of residents' annual income available for financial investment is positively correlated with their annual income $(\mathrm{p}=0.000<0.05$, Gamma $=0.513)$.

\subsection{Current Situation of Residents' Financial Management Methods}

From the survey results, $50.9 \%$ of the investment products currently held by residents are equity products such as stocks and funds, $47.4 \%$ are 
futures options and various financial derivatives, $46.6 \%$ are fixed income products such as time deposits and bonds, and $14.7 \%$ are real estate. From further cross-over analysis, it is found that there are significant differences among residents of different ages in fixed income products such as time deposits and bonds, futures, options and various financial derivatives, futures, options and real estate investment ( $\mathrm{P}$ value is less than 0.05). Residents aged 18-35 years old have made the largest proportion of investment in the first two types, and residents aged 35-60 years old have made the largest proportion of investment in the latter two types, which are related to their different investment ideas and wealth accumulation. There are significant differences among residents with different annual incomes in fixed income products such as time deposits and bonds ( $\mathrm{p}=0.001)$, futures, options and various financial derivatives $(\mathrm{p}=0.000)$. Residents with an annual income of less than 120000 yuan invest most in fixed income products such as time deposits and bonds (64.8\%). Residents with an annual income of 120,000 yuan to 300,000 yuan invest in futures, options and various financial derivatives, accounting for $74.2 \%$. Nearly $80 \%$ of residents are more inclined to invest in short-term investment within one year.

\subsection{Residents' Investment and Financial Management Effects}

After taking the investment and financial management, $83 \%$ of residents have made the improvement in many aspects to varying degrees, and there are significant differences among residents of different educational backgrounds, annual incomes and industries. Statistical analysis of the data further verifies that there is a positive correlation among residents' age, income and investment and financial management amount $(p=0.005<0.05$, Gamma=0.475). Residents of high school, vocational school or technical secondary school believe that their quality of life has been improved overall (75\%) after investment and financial management, and the proportion $(p=0.007<0.05$, Lambda $=0.079)$ is higher than that of residents with other academic qualifications. It can be seen that the overall income of people with lower education is lower, and the income from investment and financial management has a significant impact on the improvement of their quality of life. $50.0 \%$ of residents with an annual income of less than 120,000 yuan who can reasonably arrange expenditures after investment and financial management, which is significantly higher $(\mathrm{P}=0.005)$ than that of residents with other income levels. It can be seen that investment and financial management has a significant impact on the quality of life and income of residents, and the importance of residents' investment and financial management will be shown.

\section{PROBLEMS AND DIFFICULTIES FACED BY RESIDENTS IN THE PROCESS OF FINANCIAL MANAGEMENT}

\subsection{Problems Existing in Current Financial Management of Residents}

From the perspective of self-awareness, after excluding income factors, $63.2 \%$ of residents believe that they have "weak financial management awareness", $62.5 \%$ of residents believe that "they lack professional financial management counselor", $43 \%$ of residents believe that financial management products are scare, and $38 \%$ of residents believe that informal financial management channels are rampant.

\subsection{Difficulties Encountered by Residents in the Process of Financial Management}

From the results of statistical data, the difficulties encountered by residents in Guangdong Province in the process of financial management mainly include the lack of investment experience (73.8\%), followed by lack of investment knowledge $(54.8 \%)$, low risk tolerance $(54.3 \%)$, and inability to resist the products of high yields (44\%).

From further cross-over analysis, it is found that there are significant differences in the difficulties faced by residents of different regions in Guangdong Province in the financial management process ( $\mathrm{P}$ values are all less than 0.05). Among them, Shenzhen residents have insufficient investment knowledge, insufficient investment experience, inability to resist the products of high returns, and excessive wealth management products. It can be seen that residents in this area urgently need more professional knowledge and more detailed financial management services provided by various institutions. 


\section{CONCLUSION AND SUGGESTION}

\subsection{Conclusion}

Guangdong residents' understanding of investment and financial management is generally not comprehensive enough, and the degree of understanding is significantly positively correlated with academic qualifications and annual income.

Nearly $60 \%$ of residents are willing to insist on investment and financial management even if there is investment risk. It can be seen that the residents' attitude of investment and financial management is positive. Among them, residents aged 18-35 years old have the highest investment willingness, which is in line with the investment risk level of this age group. Residents' awareness of financial management has a certain connection with their academic qualifications.

From the analysis of the current financial situation of Guangdong residents, residents' financial management methods mainly include equity investments such as stocks and funds. Most residents' financial investment accounts for less than $50 \%$ of their total family income. Residents' investment amount and investment willingness will be affected by their annual income. The investment term is more inclined to short-term investment.

In the process of investment, residents mainly have difficulties such as lack of investment and financial management knowledge, lack of investment experience, inability to resist the product of high-yield and excessive financial products. These difficulties also restrict residents' investment behaviors such as product selection, investment period and investment willingness. At the same time, it also reflects the residents' weak awareness of investment and financial management, and their investment concept is not mature enough, and they are easily affected by the market and people around them, also there is a certain herd mentality.[6]

\subsection{Suggestion}

In view of the above problems, it can be seen that the investor education of residents is the primary task, and the following measures are recommended:

First, the government should improve relevant laws and regulations, cultivate a good financial environment, standardize the professional qualifications of financial advisers, and effectively protect the interests of investors.[5]

Second, financial institutions can cooperate with schools, public welfare organizations and other institutions to popularize financial knowledge by offline means such as lectures and community publicity, provide residents with financial awareness, and correctly guide residents to understand investment risks. Financial institutions should train their employees in professional ethics, standardize their professional behavior, and provide personalized services to residents.

Third, the school can carry out multi-channel financial education activities. The school can strengthen college students' financial awareness by setting up financial general courses and financial lectures, establish risk prevention awareness, and cooperate with financial institutions to carry out off-campus financial internship activities.

Fourth, trade unions can cooperate with schools and financial institutions to provide investment and financial education activities for employees in the industry, popularize the basic knowledge of financial management, understand the content of financial planning, strengthen employees' awareness of investment risk prevention, and improve employees' happiness in investment courses.[9]

Fifth, residents should actively learn investment and financial management knowledge, improve financial management awareness, establish a correct investment concept, invest rationally and do according to one's abilities.[8]

\section{AUTHORS' CONTRIBUTIONS}

This paper is independently completed by $\mathrm{Yu}$ Zeng.

\section{REFERENCES}

[1] Li Yiping. Research on Personal Finance of Ordinary Urban Residents in cities of China, Southwestern University of Finance and Economics, 2010. (in Chinese)

[2] Yilimu. Research on the Problems and Countermeasures of Residents' wealth management in Ganqika Town, Tongliao City, Inner Mongolia, Inner Mongolia University, 2017. (in Chinese)

[3] Huang Jiayao. Research on the Supply and Demand of Rural Residents' Investment and 
Financing in Hunan Province, Central South University of Forestry and Technology. (in Chinese)

[4] Qian Jin, Huang Jing, Sun Yueting, Chen Junqing, Peng Huimin, Shang Yushu. An Empirical Study on the Influencing Factors of Rural Residents' Investment and Financial Intention-Based on the Analysis of Survey Data in Jingmen City, Hubei Province, Journal of Hubei University of Economics (Humanities and Social Sciences), 2017 (10). (in Chinese)

[5] Ma Haimin. Investor protection, education first, Financial Expo (Fortune), 2017 (03). (in Chinese)

[6] Wang Yan, Fang Feifan. Investigation and Research on the Investment and Financial Management Status of Nanjing Residents, Market Research, 2013 (04). (in Chinese)

[7] Yin Haifei. Research on the behavior and the influencing factors to residents' financial behavior under the background of InternetAnalysis of survey data of urban residents in China, Journal of Xidian University (Social Science Edition), 2017 (02). (in Chinese)

[8] Lu Mengyu. Problems and Solutions in the Investment and Financial Management Activities of Chinese Residents, Accounting Learning, 2016 (21). (in Chinese)

[9] Xiao Xue, Xiong Xueping. Comparative Study on Investment and Financial Management Behaviors of Urban and Rural Residents-Based on 488 Survey Data in Tianmen City, Hubei Province, Huazhong Agricultural University, 2016. (in Chinese) 